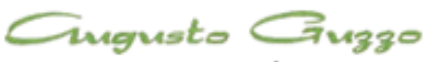

REVISTA ACADEMICA

\title{
Cultura, rito y emplazamiento: espacio, tiempo y economía en comunidades Mapuche en Chile
}

\author{
Carlos Del Valle', Claudio Maldonado² e Juan Del Valle ${ }^{3}$ \\ Recebido em: 03/09/2014. Aprovado em: 01/11/2014. Disponibilizado em: 26/12/2014
}

1. Dr. Carlos Del Valle: Doctor en Comunicación y Periodismo por la Universidad de Sevilla, España. Facultad de Educación, Ciencias Sociales y Humanidades en la Universidad de La Frontera, Temuco, Chile. Correo electrónico: carlos.delvalle@ufrontera.cl. 2. Dr. Claudio Maldonado: Doctor en Comunicación y Periodismo por la Universidad Autónoma de Barcelona. Facultad de Educación, Ciencias Sociales y Humanidades en la Universidad de La Frontera, Temuco, Chile. Correo electrónico: c.maldonado01@ufromail.cl.

3. Lic. Juan Del Valle: Licenciado en Educación y profesor de inglés por la Universidad Católica de Temuco. Investigador y Profesor de inglés en Fundación Creseres. Correo electrónico: dvalle1985@gmail.com.

\section{Resumen}

El propósito del presente trabajo es abordar el proceso de desarrollo local en contextos interculturales, considerando el caso específico de un rito indígena mapuche, a partir de tres factores: el espacio, el tiempo y la oralidad; todas como dimensiones productoras de sentido. La preocupación frente a la globalización creciente de nuestras sociedades en relación a las comunidades locales no supone regular y filtrar la globalización, sino garantizar los procesos de producción simbólica. Por ello, es más peligrosa la construcción de una carretera sobre un cementerio o un rewe indígena que el etno- turismo o la venta masiva de artesanía. En la primera actuación, se despoja a la comunidad de referentes simbólicos que aseguran la construcción permanente del sujeto-y/en-la-comunidad; en tanto que en la segunda actuación, se agregan valores que podrán co-existir si existe las garantías de construcción simbólica.

Palabras clave: mapuche, simbólico, rewe, oralidad, comunidad.

\begin{abstract}
The purpose of this research is to deal with the process of local development in intercultural contexts, by considering the specific case of an indigenous Mapuche rite, taking into account three factors: space, time and orality. All of them, as producers of sense dimensions. The current concern about the rise of globalization in our societies related to the local communities is neither intended to regulate nor to filter globalization, but to guarantee the processes of symbolic production. Therefore, it is more dangerous to construct a highway over a cemetery or rewe than encourage the ethnic tourism or the massive sale of craftwork. In the first performance, there is a kind of dispossess to the community in its symbolic model that assures the permanent construction of the subject-and/in-the-community. In the latter, it presents add values that could co-exist if there are certain guarantees of a symbolic construction.
\end{abstract}

Keywords: Mapuche, symbolic, rewe, orality, community. 


\section{Introducción}

El propósito del presente trabajo es abordar el proceso de desarrollo local en contextos interculturales, considerando el caso específico de un rito indígena mapuche, a partir de tres factores: el espacio, el tiempo y la oralidad; todas como dimensiones productoras de sentido.

De esta manera, el objetivo es comprender el desarrollo local como un proceso necesariamente endógeno y en el cual confluyen estos tres factores, como parte de un sistema complejo de significación. Lo anterior, se ilustra a través de un rito, entendido como construcción históricosimbólica permanente del sujeto en la comunidad; por lo tanto, un referente simbólico local, frente a la producción de bienes materiales, que normalmente provienen del modelo de mercado. Todo ello desde un marco de interacción permanente entre lo local y lo global, como discursos y prácticas, y los mundos posibles que a partir de dicha interacción se generan, como fundamento necesario para cualquier diseño de desarrollo local.

En síntesis, entenderemos que el desarrollo local se genera en la conjugación de la producción de bienes simbólicos del sujeto y la comunidad y de la producción de bienes materiales. Naturalmente, así como lo simbólico no es exclusivo de lo local, tampoco lo material lo es sólo de lo global. Un análisis de esta naturaleza sólo nos conduciría a un maniqueísmo idealista, que nos llevaría nuevamente a las categorías binarias de lo ancestral versus lo occidental,

\footnotetext{
${ }^{1}$ Empleamos los datos del censo 2002, debido a que el censo del año 2012 ha sido invalidado por las diferentes irregularidades detectadas durante su aplicación. Mientras el censo del año 1992 establece que la población mapuche alcanzaba un total de
}

donde el capitalismo y sus diferentes formas es sólo una manifestación del último. En este contexto, el rito, como manifestación simbólica local, incorpora factores globales a la vez que re- introduce elementos locales en su rol productor de sentido.

Esta mirada del desarrollo local a partir del complejo proceso de producción simbólico material al interior de las comunidades indígenas, constituye una forma de abordar la relación «entre las actuaciones sobre la cultura [patrimonio cultural] y un nuevo discurso de desarrollo económico que da un valor a la cultura [valor económico de la cultura]» [Aguilar, 2002], donde coexisten permanentemente, al menos, dos actuaciones sobre la cultura:

a. Su valorización material y económica, como bien de consumo que proviene de lo global y, por lo tanto, forma parte de un "diseño global", de la interculturalidad: relación culturadesarrollo, desde lo global.

b. Su valorización simbólica, como bien de sentido que proviene de un régimen de significación que forma parte de un "diseño local", de la intraculturalidad: relación cultura-desarrollo, desde lo local.

\section{Desarrollo}

\subsection{Breve sociodemografía de comunidades indígenas Mapuche en Chile}

Según los datos entregados por el Instituto Nacional de Estadística (INE), en base al Censo del año $2002^{1}$, la población en

1.282.111 personas de un total de 13.348.401; en el censo del año 2012, la población mapuche alcanza un total de 1.508.722 de un total de 1.842.607, siendo el grupo étnico mayoritario en Chile (CENSO, 2012). Sin embargo estos datos no tienen relación con el 
Chile es de 15.116.435 habitantes, de los cuales 692.192 declaran pertenecer a uno de los ocho pueblos indígenas registrados, lo que corresponde al 4,6\% ${ }^{2}$. Del total de la población indígena, 604.349 habitantes señalan pertenecer al grupo étnico mapuche, lo cual corresponde a un $87,31 \%$ del total de la población indígena en Chile (MIDEPLAN, 2005).

\subsection{Aproximaciones teóricas y conceptuales}

\subsubsection{El conflicto y la diferencia: las diferencias-en-contexto}

Entenderemos el espacio-conflicto, territorial, cultural y simbólico que define el sistema de relaciones de diferencia de las comunidades que se inter-relacionan, como un complejo social, económico y legal, donde la lógica relacional podría ser:

\section{CONFLICTO} DIFERENCIA

Tabla 1: Relación entre conflicto y diferencia. Relevamiento del conflicto

O éste:

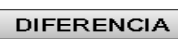

Tabla 2: Relación entre conflicto y diferencia. Relevamiento de la diferencia.
Se sugiere una reinterpretación de las situaciones a partir de la discusión sobre el relevamiento que se utiliza. Debemos entender la diferencia en nuestras sociedades como diferencias-en-contexto y no como diferencias aisladas o meras reacciones de resistencia puntual:

«No puedo afirmar una identidad diferencial sin distinguirla de un contexto y, en el proceso de hacer esta distinción, estoy afirmando el contexto [y asimismo] no puedo destruir un contexto sin destruir al mismo tiempo la identidad del sujeto particular que lleva a cabo la destrucción» [Laclau, 2000: 260].

En este sentido, las diferencias de la particularidad "indígena-mapuche" en la migración rural-urbano, reafirman el contexto en que ocurre dicha migración: la ciudad como espacio-conflicto, geográfico, cultural y simbólico. La ciudad y lo urbano, también, como un nuevo campo de interlocución; esto es, como un espacio nuevo de relaciones y de re-configuración de "unos" y "otros". Y, como insiste LACLAU, en este espacio, contexto o campo, se confunden lo particular y lo universal, lo local y lo global: «La separación -o, mejor dicho, el derecho a la diferencia- tiene que ser afirmado dentro de una comunidad global, esto es, en un espacio donde el grupo particular tiene que coexistir con otros grupos» [Laclau, 2000: 265].

En este proceso de imbricación detonado por el desplazamiento de los sujetos indígenas al espacio urbano, la dimensión identitaria no anula su

comento; en tanto, el cuestionamiento al instrumento se mantiene.

${ }^{2}$ Los pueblos considerados son aquellos reconocidos por la legislación vigente: Alacalufe, Atacameño, Aymara, Colla, Mapuche, Quechua, Rapanui y Yámana. Cabe consignar que la pregunta realizada se refiere al sentido de pertenencia de las personas mayores de 14 años. 
diferenciación frente a la sociedad mayorizada. Es un estar emplazado desde la alteridad, situación que permea el espacioconflicto con una red de sentidos que desafían los absolutismos autofundados en la intimidad de la hegemonía cultural. El emplazamiento en el territorio urbano, por parte del conglomerado indígena-mapuche, le otorga valía a su estado existencial, pero no como mera representación de un "ser" indígena, sino como "estar" desde lo indígena, situándose en el escenario interaccional a partir de la autolegitimación de sus matrices culturales, activando sistemas semióticos que ponen en tensión las "verdades" constituidas en el espacio que ahora los invita/obliga a estar desde un estado no sujeto a su propio esencialismo.

\subsubsection{Caracterización simbólica y cultural de la oralidad}

Uno de los ejemplos que podemos observar es el de la oralidad ${ }^{3}$, la cual emerge con especial fuerza los últimos años como diferencia producto de los conflictos entre indígenas y no indígenas. En este trabajo entendemos la oralidad como hecho cultural de diferenciación que surge tras la interacción de las comunidades en el espacio-conflicto, geográfico, cultural y simbólico y no como mero instrumento que permite la reducción de los procedimientos burocráticos (en los casos del sistema judicial y sanitario chileno, la oralidad es aplicada instrumentalmente en los procesos de innovación y reforma de dichos sistemas, para reducir la burocracia del sistema, pero no como hecho simbólico y cultural creador de sentido en las comunidades indígenas).

La oralidad, producto de diversos procesos de control cultural, ha sido

\footnotetext{
${ }^{3}$ Para profundizar sobre la oralidad, ver los trabajos de: [KAISER 1961]; [LABOV 1972]; [CREES 1979]; [CHAFE, 1980]; [ONG, 1987]; [HALLIDAY, 1989];
}

socializada e integrada a la cultura mayoritaria y mayorizada. Muy pocos indígenas mapuches son hablantes sólo de su propia lengua y las actuales "medidas interculturales" -no políticas sistemáticas-, reducen la cultura a sus aspectos idiomáticos y al re-introducir el idioma entre los indígenas se hace conforme al modelo mayoritario, es decir, alfabetizando la lengua y llevándola a la escritura. Como resultado, coexisten más de cinco alfabetos entre los oficiales del Estado, los de estudiosos de la lengua y los de reivindicación indígena. No obstante, hablar de una cultura oral es más que hablar de una cultura que prescinde de la escritura: es una forma particular de ver, producir, reproducir, comunicar y representar el mundo. No cambia sólo el código idiomático, sino también todo el complejo entramado de códigos culturales, sociales, religiosos, etc.

\subsection{E1 conflicto como fundamento intercultural}

Como lo explicábamos más arriba, el conflicto forma parte de la migración de las comunidades indígenas mapuches hacia un espacio-conflicto, geográfico, cultural y simbólico específico; y a partir de dicho conflicto surgen las diferencias, como es el caso de la oralidad, en el marco del control y la violencia de la escritura.

La interculturalidad constituye en la actualidad un discurso muy frecuente, particularmente ante la preocupación por los fenómenos de migración, en Europa, y los fenómenos de reivindicación indígena, en Latinoamérica. No obstante, para hablar con mayor consistencia de interculturalidad y

[BROWN y YULE, 1993]; [CARDONA, 1994]; [MARCONE, 1997]; [BLANCHE-BENVENISTE, 1998] y [MARIACA, BLONDET y CASALMIGLIA y TUSÓN, 1999]. 
comunicación intercultural, propongo las siguientes consideraciones:

a. Comprender la diversidad, la diferencia y el conflicto como factores fundantes de nuestro sistema de relaciones y no como obstáculo para dichas relaciones. El conflicto es, pues, base del desarrollo y dinámica cultural, particularmente en comunidades indígenas. Es a través del conflicto que estas comunidades han convivido en el espacio-conflicto, geográfico, cultural y simbólico: la globalización religiosa, la globalización de los Estados-nación y la globalización del mercado ${ }^{4}$ y desde estos conflictos surgen las diferencias. La dinámica del conflicto y las diferencias podemos entenderla también en la paradoja de la existencia sine qua non entre la relación universal-particular, global/local, en el sentido que plantea LACLAU:

«Esta paradoja no puede resolverse, pero su no-resolución es la precondición misma de la democracia. La solución de la paradoja implicaría que un cuerpo particular habría sido encontrado, que sería el cuerpo verdadero de lo universal. Pero en este caso lo universal habría encontrado su emplazamiento necesario y la democracia sería imposible» [Laclau, 2000: 267-268].

Siguiendo a LACLAU (2000), el conflicto pasa a ser un factor fundamental de la interculturalidad en la medida que las relaciones entre culturas devienen universal y particular, cuyo conflicto se materializa en la lucha entre la cultura de "unos" minorizada, no siempre minoritaria, y la cultura de "otros" mayorizada, no siempre pero "suficientemente" mayoritaria. Es este conflicto lo que sustenta y hace posible la interacción, la interculturalidad, el multiculturalismo y la democracia.

\footnotetext{
${ }^{4}$ Cfr. trabajos de MORENO, Isidoro [1996 y 2002].
}

En síntesis, pensar/asumir los procesos de relación intercultural como un "estar en conflicto" que permite la activación, organización y enfrentamiento de sentidos en el contexto de un espacio que se hibridiza producto del encuentro de identidades que transitan en y desde la diferencia.

Si se rompe este campo de conflicto, significa «que un cuerpo particular habría sido encontrado, que sería el cuerpo verdadero de lo universal [...] y la democracia habría terminado» [Laclau, 2000: 267]. Y también la interculturalidad y cualquier proyecto multicultural habrían terminado. En efecto, la búsqueda de un proyecto intercultural supone negociaciones, donde "unos" y "otros" «acepten la diferencia y estén dispuestos a [...] admitir la posibilidad de hacer los cambios necesarios en su propia cultura» [Olivé, 1999: 20]. Y ya sabemos qué cambios deben realizarse y qué diferencias deben aceptarse. $\mathrm{Y}$ de quienes son esos cambios. Por ejemplo preguntémonos: ¿cómo evitar en la negociación la lógica de los derechos universales y de una única juridicidad institucionalizada?, ¿o la presencia de un sistema sanitario único centrado en la hiperhigienización que trata despectivamente las formas de salud basadas en la lógica simbólica y el uso de yerbas?

De lo anterior se deprende la necesidad de reconfigurar lo que WOLTON ha denominado con el concepto de "Triángulo Infernal: Identidad - Cultura Comunicación" [Wolton, 2004:14]. Actualmente los intereses frente a este sistema de interrelaciones se ha visto superado por miradas mercantilistas que han hecho de la cultura y sus elementos materiales y simbólicos bienes de una economía cultural que anula todo proyecto ético del encuentro de la pluralidad. La emergencia exige el diseño de una política capaz de mediar por el encuentro de la diversidad dentro de los 
espacios que ha configurado la globalización a partir de un giro sustancial de las dinámicas que gobiernan la economía cultural y los modos de significación que sostienen el régimen de sentido del mundo hipermoderno: individualización, técnica y mercado [Lipovetzky, 2008].

b. Re- discutir los grandes discursos, como: derechos universales, Estado-nación, unidad nacional, fronteras, políticas de integración, justicia, accesibilidad, entre otros. Esta discusión, reiteramos, conlleva a la consolidación de un proyecto político, sin embargo, éste debe estar respaldado por la conformación de competencias interculturales, siendo de primera necesidad la consolidación de lo que RODRIGO ALSINA ha definido con el término de Competencia Comunicativa Intercultural [Rodrigo, 1999]. Para el logro de una discusión que abogue por una negociación ética entre la diferencia, las partes requieren de saberes que les permitan transitar de su mismidad a la otredad en términos de aceptación, validación e intercambio.

c. Re- pensar el espacio-conflicto, geográfico, cultural y simbólico y las políticas, economías y leyes que lo gobiernan. El espacio debe formularse a partir del reconocimiento de la otredad y la negociación como aporte de la pluralidad, disociándose de su conformación como "territorialidad

\footnotetext{
${ }^{5} \mathrm{La}$ machi es una figura normalmente pero no excluyentemente femenina y sintetiza al intermediario entre el individuo-en-su-comunidad y la divinidad. Su rol es mantener el equilibrio del bien y el mal en el plano terreno, sirviendo de nexo con el plano supraterreno. La machi representa el máximo poder espiritual de la comunidad, así como el longko representa el máximo poder civil y militar. El rol de la machi ha resistido históricamente la intervención de sistemas globalizadores: la colonización, el Estadonación y el mercado. En la actualidad la machi mantiene el control de la salud-enfermedad en las comunidades en tanto controla lo que podríamos llamar "noso-hermenéutica" -interpretación de la
}

pasiva" pasando a una "territorialidad activa" [Dematteis y Governa, 2005] en el cual el espacio ya no es mera imposición de sentidos por parte del poder, sino un "lugar" [Augé, 2004] donde habita, se encuentra y se imbrica la diversidad.

\subsection{E1 rito como emplazamiento espacio-temporal}

Ante la muerte de una machi $i^{5}$ quien la sustituirá realiza una ceremonia, de carácter simbólico-religiosa, en dos fases: (a) invocación (bailes, oraciones) para "dar descanso" al espíritu de la ausente, y su rewe ${ }^{6}$ es sacado del lugar y expulsado a las aguas del río de la comunidad; (b) invocación para "restituir" con el espíritu del nuevo machi y su rewe. La ceremonia dura, al menos, un día completo, incluyendo ambas fases, durante la cual se combinan cantos, bailes y oraciones; todas ellas manteniendo una perfecta circularidad espacial.

Es una ceremonia autorreferente, pues la/el machi restaura el "orden de las cosas", alterado por su propia ausencia (muerte). Lo interesante de esta ceremonia es que, muy recientemente, ocurre en espacios nuevos de convivencia-conflicto, ya no rurales en un sentido tradicional -naturales, donde tienen lugar las representaciones totémicas de que

enfermedad en su dimensión oral y no escrita; pese al intervencionismo estatal. Recientemente el Estado chileno anunció la prohibición del uso de yerbas tradicionales que constituyen la base de la medicina tradicional mapuche.

${ }^{6} \mathrm{El}$ rewe, siguiendo una descripción un tanto "genérica", a partir de los trabajos de Claude LÉVISTRAUUS, es una especie de representación totémica que sintetiza la divinidad actuando en el individuo y la comunidad. El rewe es propiedad de una comunidad determinada y, por lo tanto, representa la dinámica cultural y simbólica de dicha comunidad. El rewe es tutelado por una machi y pertenece a un lof o comunidade. 
habla LÉVI-STRAUSS ${ }^{7}$, sino también urbanas. En una dialéctica espacial permanente, en la cual interactúan indígenas y no indígenas en un espacio que es al mismo tiempo rural (natural) y urbano (artificial), con instalaciones eléctricas, edificaciones (la ceremonia se lleva a cabo en una escuela); ciertas temporalidades propias de lo urbano, como la hora y el día regidos ya no por una temporalidad cíclica-natural, sino cronométrica (al finalizar las clases, dando tiempo a que asistan quienes viajan desde la ciudad al finalizar sus actividades laborales, incluido el machi): ¿dónde están las fronteras?, ¿dónde podemos demarcar con claridad lo urbano y lo rural? ¿No es más razonable pensar que la frontera es un nolugar que puede ser cualquiera y ninguno al mismo tiempo? Como señala BECK: «las culturas glocales que se están abriendo paso ya no están vinculadas a ningún lugar ni a ningún tiempo. Carecen de contexto» [Beck, 1998: 86]. Y esto no es menos conflictivo que la mirada tradicional de que las fronteras están - ahí, puesto que ahora aparecen en cualquier lugar, generando más que armonizaciones y convergencias, dilemas y divergencias. Pero los dilemas y las divergencias, como los conflictos, producen sentido y dinamizan las culturas y las relaciones entre culturas. Y no sólo porque la ceremonia indígena es en sí la representación de un conflicto entre el bien y el mal -pero también por ello -, sino porque pone de manifiesto permanentemente la discusión sobre lo que es propio y lo que es ajeno: el conflicto constante entre lo totémicoreligioso-natural-rural y lo profano-cristianoartificial-urbano.

El conflicto no está en la existencia de lo urbano: sino en que lo urbano no representa

\footnotetext{
${ }^{7}$ Me refiero particularmente al trabajo de LÉVISTRAUSS, Claude [1964]: El pensamiento salvaje, México D.F., FCE [Edición posterior en español], en el cual juega magistralmente con la dialéctica
}

sólo "progreso y desarrollo", como en el imaginario colectivo, sino que representa al mismo tiempo "pérdida y desnaturalización". El sincretismo es un conflicto permanente y productor de mundos-espacios posibles en la convivencia. En efecto, «las preservación es siempre el mejor recurso popular para reproducirse y reelaborar su situación» [García Canclini, 1989: 218].

\subsection{El rito de emplazamient económico- cultural}

Mientras los procesos de globalización, especialmente materiales vinculados a la economía, valorizan la cultura como un bien de cambio y como un recurso de sobrevivencia; los procesos locales, como los ritos, permiten una revalorización simbólica de la cultura, construyendo al sujeto-y/en-lacomunidad:

«Las sociedades de la tradición dedican mucho tiempo y energía a producir los sujetos y la organización social que los mantiene unidos [...] Las sociedades de la tradición dedican mucho tiempo a actividades ceremoniales y rituales que van modelando a los sujetos en sus hábitos mentales y motrices, que los sitúan en los sistemas de parentesco, en la aldea, en el ambiente de la fauna, de la flora, de los elementos y de los seres que pueblan sus mundos interiores mágicos y religiosos [...] No son actividades productivas en el sentido corriente del término [...] Sin embargo, son actividades productivas de un modo diferente, pero igualmente esencial: producen sujetos humanos y sociabilidad» [Warnier, 2002: 93].

natural/cultural, salvaje/racional, pero no como oposiciones binarias excluyentes, sino como imaginarios productores de sentido en nuestra sociedad. ¿Cuáles son realmente las fronteras que hay en este juego dialéctico? 
En nuestro análisis, en la oposición entre la producción simbólica del sujeto-y/en-lacomunidad y la producción económica de la cultura, entendemos que ambos procesos interactúan y se combinan permanentemente; donde la producción económica de la cultura obedece al «camino a seguir por determinados grupos sociales que siempre estarán situados en un papel de dependencia con respecto al poder» [Aguilar, 1998: 153].

La producción simbólica de los sujetosy/en-la-comunidad es un proceso evidentemente local y endógeno, cuyo propósito fundamental es auto- producir a los sujetos y las comunidades culturales a partir de los rasgos culturales [Barth, 1976] propios de las comunidades. Y como proceso cumple dos funciones complementarias:

a. En lo local, fortalece a los sujetosy/en-la-comunidad, otorgando elementos de identificación, recuperando la memoria colectiva, dando sentido y llenando el vacío que deja la existencia meramente material a que nos tienen acostumbrados los procesos globalizadores, en lo que BECK llama "industrias de la imaginación" [Beck, 1998], donde «formas de vida locales se remueven y rellenan con 'prototipos' que proceden social y espacialmente de lugares completamente distintos» [Beck, 1998: 86].

b. En lo global, preparan a los sujetosy/en-la-comunidad para enfrentar los desafíos de la globalización. Sería impensable la valorización económica de la cultura como recurso, sin los procesos de afianzamiento simbólico. Son los procesos simbólicos los que aseguran la sobre- vivencia material de las comunidades, donde «la producción masiva de símbolos e informaciones culturales no origina el surgimiento de algo que se pueda parecer a una 'cultura global'» [Beck, 1998: 87].

La dimensión ritual, por su parte, formula una discursividad, que siguiendo
AUGÉ, deviene en lenguaje político [Augé, 2006]. Consideramos los aportes de AUGÉ sobre el rito en cuanto se reconoce que éste genera una tensión entre los lenguajes de la identidad y los lenguajes de la alteridad. El nuevo escenario que se ha configurado por las exigencias migratorias impuestas por la globalización, hacen que la otredad se instale en los marcos de una sociedad que históricamente ha generado prácticas de exclusión y desligitimación del mundo mapuche, lo cual se potencia si se acepta que los otros ya no están fuera del egotexto cultural dominante, sino situados en sus propios márgenes culturales. De este modo, el exotismo está en "nuestro mundo", convive en los mismos sistemas de referencia social, económicos y simbólicos, por tanto la alteridad se hace presente en la instantaneidad de lo cotidiano. No es otro del afuera, como mera dicotomía, es una alteridad innovada que se constituye en la hibridación cultural. Compréndase que el lenguaje de la identidad se válida en tanto existencia de la alteridad, sin embargo ahora, esa alteridad convive en los espacios de pertenencia en los cuales ya existen otros marginados. La alteridad indígena-mapuche viene a nutrir el campo cultural y a problematizar el lenguaje de la identidad esencial.

De aquí que el rito se transforme en un lenguaje político, visto desde la perspectiva de la performatividad indígena. Lenguaje Político en tanto tensiona el encuentro con la sociedad mayoritaria-mayorizada, transgrediendo su normalización. El rito desafía el estaticismo dominante del lenguaje de la identidad autofundada, exigiendo el reconocimiento de una colectividad que se emplaza y que traslada sus sistemas creenciales a los dominios de la urbe. 


\section{Consideraciones finales}

Siguiendo el planteamiento inicial, el caso del rito indígena mapuche como construcción simbólica del sujeto-y/en-lacomunidad, nos da cuenta de lo siguiente:

Junto con la valorización material que adquiere la cultura en los crecientes procesos de globalización económica, como característica de las actuaciones de la globalización, encontramos procesos de revalorización simbólica de los sujetos-y/en-lacomunidad, como característica de las actuaciones de lo local en interacción con lo global, puesto que además de re- introducirse lo simbólico local (oralidad y rito), se incorporan elementos de las culturas globales (tiempo y mercado); y amabas actuaciones se producen en nuevos espacios comunes de conflicto, que no son ni rurales ni urbanos, sino que ambos y ninguno a la vez. Son nolugares.

El desarrollo local, como lo muestra el caso del rito indígena mapuche, es un proceso en el cual ante las actuaciones desde lo local y lo global, «las culturas tradicionales se han desarrollado transformándose» [García Canclini, 1989: 200], donde las transformaciones son múltiples y variadas y tanto materiales como simbólicas. Mientras lo simbólico otorga sentido e identidad, lo material permite la sobre- vivencia.

La relectura del desarrollo local no es incompatible con una lectura de los procesos interculturales como procesos de conflicto, en los cuales es precisamente el conflicto el que genera sentido y desarrollo. Lo anterior es particularmente válido para las culturas indígenas que, como la mapuche en Chile, tienen un referente histórico de conflictos: con las otras comunidades indígenas, con los europeos durante la conquista y la colonia, con el Estado-nación y, actualmente, con el mercado. $\mathrm{Y}$ dichos conflictos se dan en espacios geográficos, simbólicos y culturales.
La preocupación frente a la globalización creciente de nuestras sociedades en relación a las comunidades locales no supone regular y filtrar la globalización, sino garantizar los procesos de producción simbólica. Por ello, es más peligrosa la construcción de una carretera sobre un cementerio o un rewe indígena que el etno- turismo o la venta masiva de artesanía.

En la primera actuación, se despoja a la comunidad de referentes simbólicos que aseguran la construcción permanente del sujeto-y/en-la-comunidad; en tanto que en la segunda actuación, se agregan valores que podrán co-existir si existe las garantías de construcción simbólica. En este sentido, de lo que se trata es de entender más que formas excluyentes de relación, formas que se incluyen; aunque no convergentemente, sino en divergencia permanente: «Con corresponsabilidad y compromiso equitativo, de las nuevas organizaciones, de los distintos agentes [...] y el reconocimiento de la compleja articulación entre lo global, la formación del Estado y lo local» [Rodríguez, 2000: 119]'.

$\mathrm{Y}$ en esta dinámica los procesos locales interactúan con los procesos globales y los incorporan «otorgando múltiples significados, dando pie a la creación de formas sociales nuevas pero también a la transformación, reinvención y readecuación de procesos ya existentes» [Bueno, 2000: 8].

\section{Bibliografía}

AGUILAR, Encarnación (1998): Patrimonio etnológico. Nuevas perspectivas de estudio, Sevilla, Instituto Andaluz del Patrimonio Histórico. 
(2002): Cultura, desarrollo local y globalización, Sevilla, Universidad de Sevilla. [Apuntes de clase].

AUGÉ, Marc (2006) Hacia una antropología de los mundos contemporáneos, Barcelona, Gedisa.

(2004) Los no lugares. Espacios del anonimato. Una antropología de la sobremodernidad, Barcelona, Gedisa.

BARTH, Fredrick (1976): Los grupos étnicos y sus fronteras. La organización social de las diferencias culturales, México D.F., FCE.

BECK, Ulrich (1998): ¿Qué es la globalización? Falacias del globalismo, respuestas a la globalización, Barcelona, Paidós.

BODEI, Remo (2000): “Los sin patria”, en SILVEIRA, Héctor (Ed.): Identidades comunitarias y democracia, Madrid, Trotta.

BONFIL BATALLA, G. (1983): “Lo Propio y Lo Ajeno. Una aproximación al problema del control cultural" en UNESCO, en Educación, Etnias y Descolonización en América Latina, Vol. 1, pp. 249-256 México: Instituto Indigenista Interamericano y OREALC.

- (1986): "La teoría de control cultural en el estudio de los procesos étnicos" Anuario Antropológico, Brasilia: Editora Universidade de Brasilia.
(1987): México Profundo: Una Civilización Negada, México: Secretaría de Educación Pública y Centro de Investigaciones y Estudio Superiores en Antropología Social.

BUENO, Carmen (Coord.) (2000):

Globalización: una cuestión antropológica, México D.F., CIESAS.

CARRASCO, Hugo (2001): "Rasgos identitarios del discurso público mapuche”, en Universum, Talca, Universidad de Talca.

(2002): “El discurso público mapuche: noción, tipos discursivos e hibridez", en Estudios Filológicos, no 37, Valdivia, Universidad Austral de Chile.

COHN, Daniel (1996): Ciudadanos de Babel: apostando por una democracia multicultural, Madrid: Talasa.

DEMATTEIS, Giuseppe y GOVERNA, Francesca (2005) “Territorio y Territorialidad en el desarrollo local. La contribución del Modelo Slot.” Boletín de la A.G.E. N 39, 31 58. 2005.

DEL VALLE, Carlos y MORENO, Javier (2004) (Eds.): Comunicación intercultural. Genealogía, crítica y experiencias. Instituto Europeo de Comunicación y Desarrollo, Sevilla, España. En Prensa.

DEL VALLE, Carlos y MORENO, José (2004): "Comunicación intercultural y desarrollo endógeno", en ENCINA, Javier 
(Ed.). Democracias participativas e intervención social comunitaria desde Andalucía, Editorial Atrapasueños/Universidad Pablo de Olavide, Sevilla, España. ISBN 84-607-8469-X. pp. 221-252.

\section{DEL VALLE, Carlos (1998):}

"Reconstrucción de la historia en el discurso jurídico mapuche, a propósito de una demanda de reivindicación territorial", Lengua y Literatura Mapuche, Universidad de La Frontera, Chile. No 8, pp. 233-242.

-------- (2000a): "La estructura argumentativa de un tipo particular de discurso jurídico", Lengua y Literatura Mapuche, Universidad de La Frontera, Chile. No 9, pp. 169-176.

(2000b): "La producción de comunicación (medial) en contextos educativos interculturales", Educación y Humanidades, Universidad de La Frontera, Chile. $\mathrm{N}^{\circ}$ 9, pp. 27-37.

(2001a): "El uso de descripciones factuales como estrategias comunicativas de legitimación discursiva: el recurso de Ley de Seguridad del estado en el proceso judicial de 12 mapuches en la IX Región (Dic. 1997Abril 1999)", Estudios Criminológicos y Penitenciarios, Gendarmería de Chile y Ministerio de Justicia de Chile. No 3, pp. 117130. (2001b): "La estructura argumentativa de un tipo particular de discurso jurídico. El caso de cuatro demandas de reivindicación territorial mapuche (IX Región-Chile) y sus implicancias identitarias", Estudios Criminológicos y Penitenciarios, Gendarmería de Chile y Ministerio de Justicia de Chile. No 2, pp. 25-40. - (2002a): Comunicar la salud. Entre la equidad y la diferencia. Ediciones Universidad de La Frontera, Temuco, Chile. ISBN 956-236-144-6. 161 páginas. - (2002b): Coordinador de la Edición No 26 de la revista Razón y Palabra, Primera Revista Electrónica en América Latina Especializada en Tópicos de Comunicación, con el tema Aportes y Perspectivas de los estudios de la Comunicación. (2002c): "El proceso judicial de 12 mapuches en Chile: entre el racismo de estado y la violencia del lenguaje", Razón y Palabra, Primera Revista Electrónica en América Latina Especializada en Tópicos de Comunicación, $\mathrm{N}^{\mathrm{o}} 26$.

------- (2002d): "La estructura argumentativa de un tipo particular de discurso jurídico. El caso de cuatro demandas de reivindicación territorial mapuche (IX Región - Chile) y sus implicancias identitarias", Ámbitos. Revista Andaluza de 
Comunicación, Universidad de Sevilla, España. Nos 7 y 8, pp. 181-196.

(2002e): "La estructura argumentativa de un tipo particular de discurso jurídico. El caso de cuatro demandas de reivindicación territorial mapuche (IX Región - Chile)", Revista de la Facultad, Facultad de Derecho y Ciencias Sociales, Universidad Nacional del Comahue/PubliFadecs, Argentina. Año 7, $\mathrm{N}^{\circ}$ 7, pp. 41-50.

(2002f): "Los desafíos interculturales de la justicia en Chile: De la violencia y el racismo del lenguaje a la tecnologización y economía del lenguaje y los procedimientos", en revista electrónica Orígenes, del Ministerio de Educación y del Ministerio de Planificación, Chile. (2003a): "Hacia una pedagogía de la comunicación intercultural: bases desde la producción oral, radial y mediática", Comuniquiatras, Revista Internacional, Doctorado Interdisciplinar en Estudios Culturales: Literatura y Comunicación, del Departamento de Comunicación Audiovisual, Publicidad y Literatura de la Facultad de Comunicación de la Universidad de Sevilla, España. - (2003b): "Interculturalidad y justicia.

De la violencia de la escritura a la economía procedimental de la oralidad", Ámbitos.
Revista Andaluza de Comunicación, Universidad de Sevilla, España, $N^{\circ}$ s 9 y 10, Sevilla, pp. 87-101.

(2003c): "La construcción social del llamado 'conflicto mapuche' en Chile, en publicaciones periódicas electrónicas realizadas por los propios mapuches...", revista electrónica Orígenes, Ministerio de Educación /Ministerio de Planificación, Chile.

(2003d): "La identidad en un doble juego: resistencia y apertura...o el aprendizaje del cinismo. La construcción social del llamado "conflicto mapuche" en Chile, en publicaciones electrónicas realizadas por los propios mapuches", Diálogos de la comunicación, $\quad \mathrm{N}^{\circ}$ 66, Federación Latinoamericana de Facultades de Comunicación Social, FELAFACS, Lima, pp. 90-97. (2003e): "Pertinencias y énfasis en la formación sobre comunicación para el desarrollo: diagnóstico y perspectivas de la experiencia iberoamericana”, en Redes.Com, Instituto Europeo de Comunicación y Desarrollo, Sevilla. ISSN 1696-2079, pp. 255272.

(2004a): "Comunicación, espacios y migración intraregional: Rito y oralidad como formas de contra poder e intertextualidad", Global Media Journal en español, Centro de 
Investigación en Comunicación e

Información (CINCO), del Instituto Tecnológico de Monterrey, México/Departamento de Comunicación y Artes Creativas de la Universidad de PurdueCalumet, Hammond, Indiana, Estados Unidos.

(2004b). "Comunicación, participación y el dilema existencial del Estado frente a las nuevas lógicas democráticas y ciudadanas: discursos y experiencias participativas en Chile", en SIERRA, Francisco y ENCINA, Javier (2004) (Eds.). Universidad Pablo de Olavide. En Prensa.

(2004c): "Conflicto y síntesis en un sistema de salud público inserto en comunidades mapuches. Hospital Makewe", en ARRIAGA, FLÓREZ, et al. (Eds.): Sociedades y Culturas. Nuevas Formas de Aproximación Literaria y Cultural. Sociedad Española de Literatura y Cultura Popular, SELICUP/Universidad de Sevilla/Arcibel Editores. ISBN 84-933318-8-0. [CD ROM]. -------- (2004d) (Ed.): Culturas en la Sociedad del Conocimiento, UPLA/UFRO/ U.AUSTRAL Editores. En Prensa.

------- (2004e): "Desarrollo local y patrimonio cultural: el rito como construcción simbólica del sujeto y la comunidad frente a la producción económica de la cultura", en Revista Lider, Centro de
Estudios del Desarrollo Local y Regional (CEDER), Universidad de Los Lagos, Osorno. Año 9, No 12, $2^{\circ}$ Semestre de 2003, pp. 63-81.

(2004f): "Discurso, oralidad e interculturalidad en el sistema procesal penal chileno: economía procedimental, simulación y poder", Discurso, Universidad de Sevilla, España, pp. 87-101.

(2004g): “Genealogía crítica de la comunicación intercultural: Mediocentrismo e invisibilización de lo étnico en los estudios interculturales", en Revista Sphera Pública, Universidad San Antonio de Murcia, España, pp. 171-196.

(2004h). "La representación de los indígenas mapuches (Araucanos) de Chile en las Relaciones de Sucesos publicadas en España: recuperación de la memoria histórica y aproximaciones al debate intracultural e intercultural", en Revista Zer, Universidad del País Vasco, España, pp. 121-136.

(2004i): “Los desafíos de la interculturalidad en la transición de la justicia penal en Chile: cuentas pendientes", Lengua y Literatura Mapuche, $\mathrm{N}^{\mathrm{o}} 10$, Universidad de La Frontera, pp. 217-226.

-------- (2004j). Metainvestigación de la comunicación en Chile. Crítica y Tendencias, Temuco, Ediciones Universidad de La Frontera. ISBN 956-236-155-1. 130 páginas. 
(2004k). "Políticas culturales en Chile durante los últimos 30 años: de la invisibilización a la politización de la cultura", en SIERRA, Francisco; MORENO, Javier (Eds.) (2004) Comunicación y desarrollo en la sociedad global de la información: economía, política y lógicas culturales, Instituto Europeo de Comunicación y Desarrollo/Centro Iberoamericano de Comunicación Digital, CICO/Unión Latina de Economía Política de la Información, la Comunicación y la Cultura, ULEPICC, Sevilla, España. ISBN: 84-607-8389-8, pp. 169-182.

FOUCAULT, Michel (1992): Genealogía del racismo, Madrid, La Piqueta. - (1992): Vigilar y castigar, Madrid, La

Piqueta.

(1995): La verdad y las formas jurídicas, Barcelona, Gedisa.

GARCÍA CANCLINI, Néstor (1989): Culturas híbridas. Estrategias para entrar y salir de la modernidad, México D.F., Grijalbo.

GRIMSON, Alejandro (2000): Interculturalidad y comunicación, Buenos Aires, Norma.

LABOV, William (1972): The transformation of experience in narrative syntax. Language in the Inner City
Philadelphia, The University of Pennsylvania Press.

LACLAU, Ernesto (2000): “Universalismo, particularismo y el tema de la identidad", en SILVEIRA, Héctor (Ed.): Identidades comunitarias y democracia, Madrid, Trotta. LÉVI-STRAUSS, Claude (1964): El pensamiento salvaje, México D.F., FCE. LIPOVETSKY, Guilles (2008): Los Tiempos Hipermodernos. Barcelona: Anagrama. MARIACA, Guillermo (1999): Los refugios de la utopía. Apuntes teóricos para una política Inter-cultural, Bolivia, Sierpe. MARCONE, Jorge (1997): La oralidad escrita. Sobre la reivindicación y reinscripción del discurso oral, Perú, Fondo Editorial.

MORENO, Isidoro (1996): "Etnicidades, estados, migraciones y violencia: el carácter obsoleto del modelo de Estado-nación", en Diversidad étnica y conflicto en América Latina, México D.F., Plaza y Valdés. (2002): "Religión, estado y mercado. Los sacros de nuestro tiempo", en ZAMBRANO, Carlos (Ed.): Confesionalidad y política. Confrontaciones multiculturales por el monopolio religioso, pp. 35-52, Bogotá, Universidad Nacional de Colombia. OLIVÉ, L. (1993): Ética y Diversidad Cultural, México: Instituto de Investigaciones Filosóficas. 
(1999): Multiculturalismo y

Pluralismo, Madrid: Paidós.

ONG, Walter (1987): Oralidad y escritura.

Tecnologías de la palabra, México, Fondo de

Cultura Económica.

RODRIGO, Miquel (1999): La comunicación intercultural, Madrid, Anthropos.

RODRÍGUEZ, Guadalupe (2000): “Organización para la calidad. La apropiación y reconfiguración de la globalización entre los ganaderos de leche alteños", en BUENO, Carmen (Coord.): Globalización: una cuestión antropológica, México D.F., CIESAS.

TIERNEY, P.; AILLAPÁN, L. (1998): El Altar más Alto, New York, Viking Press.

WARNIER, Jean-Pierre (2002): La mundialización de la cultura, Barcelona, Gedisa.

WOLTON, D. (2004) La otra mundialización. Los desafíos de la cohabitación cultural global. Barcelona, Gedisa.

\section{Bibliografía Consultada}

AYLWIN, José (1999): Pueblos indígenas de

Chile: antecedentes históricos y situación actual, Temuco, Instituto de Estudios Indígenas-Universidad de La Frontera.

BACIGALUPO, ANA (1994): “Adaptation and variation of machi healing roles", en The power of the machis. The rise of female shaman healers and priestesses in mapuche society, Michigan (USA), University Microfilms International.

BENGOA, José (1987): Historia del pueblo mapuche, Santiago de Chile, Sur Ediciones.

BLANCHE-BENVENISTE, Claire (1998):

Estudios lingüísticos sobre la relación entre oralidad y escritura, Barcelona, Gedisa.

CARDONA, Giancarlo (1994): Los lenguajes del saber, Barcelona, Gedisa.

CASMIR, FRED (1993): Tirad, Culture Buildings: A paradigm shift for International and Intercultural Communication, Londres, S.A. Deeetz.

CASTELLS, Manuel (1997): The power of identity: the information age- economy, society and culture, Londres, Blackwell Publishers.

CITARELLA, LUCA (1995): Medicinas y culturas en La Araucanía, Santiago de Chile, Sudamericana.

CLIFFORD, J. (1997): The ethnicity reader. Nationalism, multiculturalism and migration, Cambridge, Polity Press.

DAVINSON, Guillermo (2000): Reforma al sistema judicial chileno: implicancias para el pueblo mapuche, Temuco: Instituto de Estudios Indígenas-Universidad de La Frontera.

DERRIDA, Jacques (1971): De la gramatología, Buenos Aires, Siglo XXI. 
(1988): Márgenes de la filosofía, Madrid, Cátedra.

(1989): La escritura y la diferencia,

Barcelona, Anthropos.

DURÁN， TERESA (1994): “Contacto

Interétnico Chileno Mapuche en la 9na.

Región”, en CUHSO, Vol. $\mathrm{N}^{\circ}$ 1, Temuco, Chile.

FRIES, Lorena y MATUS, Verónica (1999):

El derecho. Trama y conjura patriarcal, Santiago de Chile, ARCIS.

GREBE, Ester (1972): “Cosmovisión mapuche”, en Cuadernos de la Realidad Nacional, No 14, Santiago de Chile.

(1973): "El kultrún mapuche: un microcosmo simbólico", en Revista Musical Chilena, Santiago de Chile.

(1974): "Presencia del dualismo en

la cultura y música mapuche", en Revista Musical Chilena, Santiago de Chile.

HALLIDAY, M.A.K. (1985/1989): Spoken and written language, Oxford, University Press.

JAMESON, Fredric (1998): Estudios culturales: reflexiones sobre el multiculturalismo, Madrid, Paidós.

LIE, Rico (2002): Spaces of intercultural communication. an interdisciplinary intriduction to communication, culture and globalizing/localizing identities, Londres, Hampton Press.
LIE, Rico \& SERVAES, J. (2000): "Globalization, consumption and identity towards researching nodal points", en WANG, G.; SERVAES, J. \& GOONASEKERA, A.: The new communication landscape. demystifyng media globalization, Londrés, Routledge.

LÓPEZ, Luis et al. (1998): Sobre las huellas de la voz, Madrid, Morata.

MAX-NEEF, Manfred et al. (1998):

Desarrollo a escala humana, Barcelona, España.

POTTER, Jonathan (1998): La representación de la realidad, Barcelona, Gedisa.

RESTA, Eligio (2000): "La comunidad inconfesable y el derecho fraterno", en SILVEIRA, Héctor (Ed): Identidades comunitarias y democracia, Madrid, Trotta.

RODRIGO ALSINA, Miquel (1989): La Construcción de la Noticia, Barcelona, Paidós.

(1999a): La comunicación intercultural, Madrid, Anthropos. (1999b): Bibliografía comentada de comunicación intercultural, Sevilla, Universidad de Sevilla. [Apuntes biblioteca Facultad de Comunicación].

SAMOVAR, L. \& PORTER, R. (1998): Communication intercultural: a reader, Wadsworth, Belmont. 
SIERRA, Francisco (1998): “Televisión educativa y desarrollo local" en Ensayos de Comunicación Educativa. Cuaderno de Trabajo, Año 1, Número 2, pp. 25-39, México D.F., Primera Época, Año 1.

-------- (2001a): “Comunicación global, intervenciones locales. La espiral del silencio en la guerra total y prolongada", en VILLAFAÑE, Justo (Coord.): Los espacios para la comunicación, Madrid, Universidad Complutense/Ayuntamiento de Madrid.

(2001b): "Navegaciones y migraciones culturales. Lógicas sociocomunicativas en la sociedad del conocimiento" en Sphera Pública. Revista de Ciencias Sociales y de la Comunicación, número 1, pp. 135-153, Murcia, Universidad Católica de San Antonio.

(2002): "La agenda de los Estudios

Culturales en comunicación. Cartografiar el cambio social" en BERNAL, Manuel (Coord.): Cultura Popular y Medios de Comunicación. Una aproximación desde Andalucía, Sevilla, Comunicación Social Ediciones y Publicaciones.

SILVEIRA, Héctor (2000): Identidades comunitarias y democracia, Madrid, Trotta.

SINGH, Katar (1999): Rural development.

Principles, policies and management, Londres, Sage.

WEIL, Simone (1997): Echar raíces, Madrid, Trotta.
ZAMBRANO, C. (Ed): Confesionalidad Política. Confrontaciones multiculturales por el monopolio religioso, Bogotá, Universidad Nacional de Colombia.

RECURSOS ELECTRÓNICOS

(Para las referencias a los recursos electrónicos, se utiliza la norma ISO-690-2)

ACCIÓN GLOBAL DE LOS PUEBLOS (Italia). [en línea]: ACCIÓN GLOBAL DE LOS PUEBLOS < http://www.agp.org> [Consulta: 30 sept. 2002].

ALIANZA POR UN MUNDO SOLIDARIO Y RESPONSABLE (Brasil). [en línea]: ALIANZA POR UN MUNDO SOLIDARIO Y RESPONSABLE $<$ http://www.alternex.com.br/pacs>

[Consulta: 30 sept. 2002].

MUNDIAL

DE

POBLADORES (Turquía). [en línea]:

ASAMBLEA MUNDIAL

DE

\section{POBLADORES}

$<$ http://www.laneta.apc.org/hic-al>

[Consulta: 30 sept. 2002].

ASOCIACIÓN DE TELECENTRISTAS ACTIVOS DE CHILE (Chile). [en línea]: ASOCIACIÓN DE TELECENTRISTAS ACTIVOS DE CHILE <http://atach.cl> [Consulta: 20 dic. 2002].

ASOCIACIÓN PARA EL PROGRESO DE LAS COMUNICACIONES. [en línea]: ASOCIACIÓN PARA EL PROGRESO DE LAS COMUNICACIONES 
$<$ http://www.apc.org $>$ [Consulta: 20 dic. 2002].

ATTAC (Francia). [en línea]: ATTAC $<$ http://www.attac.org> [Consulta: 30 sept. 2002].

COMUNICACIÓN Y CIUDADANÍA (Estados Unidos). [en línea]: COMUNICACIÓN Y CIUDADANÍA $<$ http://www.ecuanex.net.ec/foro_comunic acion> [Consulta: 30 sept. 2002].

COMUNIDAD

WEB

DE

MOVIMIENTOS SOCIALES (Ecuador). [en línea]: COMUNIDAD WEB DE MOVIMIENTOS SOCIALES

$<$ http://movimientos.org $>$ [Consulta: 30 sept. 2002].

COLECTIVO DE CONTRAIN FORMACIÓN. [en línea]: COLECTIVO DE CONTRAINFORMACIÓN

$<$ http://www. adbusters.org> [Consulta: 20 dic. 2002].

Z NET(Estados Unidos). [en línea]: Z NET $<$ http://www.zmag.org $>$ [Consulta: 30 sept. 2002].

INICIATIVA CONTRA LA GLOBALIZACIÓN ECONÓMICA (República Checa). [en línea]: INICIATIVA CONTRA LA GLOBALIZACIÓN ECONÓMICA < <ttp://inpeg.ecn.cz> [Consulta: 30 sept. 2002].
MARCHA MUNDIAL DE LAS MUJERES (Canadá). [en línea]: MARCHA MUNDIAL DE LAS MUJERES <http://www.ffq.qc.ca/marche2000> [Consulta: 30 sept. 2002]. MOVIMIENTO ANTIGLOBALIZA CIÓN. [en línea]: MOVIMIENTO ANTIGLOBALIZACIÓN

$<$ http://www.indymedia.org> [Consulta: 20 dic. 2002].

MOVIMIENTO PARA LA RESITENCIA GLOBAL (España). [en línea]: MOVIMIENTO PARA LA RESITENCIA GLOBAL < http://www.pangea.org/mrg> [Consulta: 30 sept. 2002].

RED ALTERNATIV (España/Francia). [en línea]: RED ALTERNATIV $<$ http://conjuntos.fortunecity.es/social/6/ $>$ [Consulta: 30 sept. 2002].

RED CHILENA POPULAR E INDÍGENA (Chile). [en línea]: RED CHILENA POPULAR E INDÍGENA $<$ http://www.geocities.com/CapitolHill/63 77> [Consulta: 30 sept. 2002].

UNIVERSIDAD DE LA FRONTERA (Chile). [en línea]: RED COMUNITARIA $<$ http://redcomunitaria.cl> [Consulta: 20 dic. 2002] 